\title{
UMA IMAGEM-CONTRASTE: \\ A IRONIA ENTRE DISJUNÇÕES SONORAS E VISUAIS
}

Marcus Pereira Novaes*

Antonio Carlos Rodrigues de Amorim**

\begin{abstract}
RESUMO: As relações entre imagens e (re)cognição são destacáveis nas críticas sobre os primados da representação, um dos pilares das contribuições da filosofia de Gilles Deleuze para os estudos do campo da educação. A partir da proposição do conceito de imagem-contraste, que articula o visual e o sonoro na apresentação da imagem cinematográfica, apresentam-se neste artigo contribuições para se deslocarem os sentidos mais usuais de percepção do mundo e das aprendizagens derivadas da relação dos sujeitos sobre o real, dedicando-se especialmente à análise de um filme de Stanley Kubrick. Indicam-se características constituidoras da imagemcontraste que questionam uma natureza humana privilegiada quando se nomeiam os sujeitos da educação. Destacase também o uso da ironia em sua conexão com o humor, intensificando essa imagem-contraste.
\end{abstract}

PALAVRAS-CHAVE: imagem-contraste; educação; cinema; ironia.

\section{A CONTRAST-IMAGE:} THE IRONY BETWEEN SOUND AND VISUAL DISJUNCTIONS

\begin{abstract}
The relationships between images and (re)cognition are highlighted in the criticisms about the primacy of representation, one of the pillars of the contributions of Gilles Deleuze's philosophy to the studies in the field of education. Based on the proposition of the contrast-image concept, which articulates the visual and the sound aspects in the presentation of the cinematographic image, this article presents contributions to shift the most usual senses of perception of the world and of the learning derived from the subjects' relationship about what is real, especially considering the analysis of one film by Stanley Kubrick. We have pointed out constituting characteristics in the contrast-image that question a privileged human nature when subjects of education are named. The use of irony in its connection with humor is also highlighted, intensifying this contrast-image.
\end{abstract}

KEYWORDS: contrast-image; education; cinema; irony.

\footnotetext{
* Doutor em Educação. Linguagem e Arte em Educação. Grupo Olho - Faculdade de Educação da Universidade Estadual de Campinas. E-mail: novaes.marcus@hotmail.com ORCID: https://orcid.org/0000-0001-6513-8367

** Doutor em Educação. Professor na Faculdade de Educação da Universidade Estadual de Campinas.

E-mail: acamorim@unicamp.br ORCID: https://orcid.org/0000-0002-0323-9207
} 
Nossa constituição de sujeitos é muito influenciada pelos contatos imagéticos que temos, atravessados por discursos que modelam e classificam certos modos de perceber, sentir e agir, articulando um ao outro, geralmente os padronizando. Em nossos encontros com imagens, muitas vezes, estabelecem-se processos de sujeição, podendo representar-nos em consciências que operam e valoram juízos. São consciência e sujeito, frutos de um discurso que nos educam segundo modelos universais, ensinando-nos padrões que dependem de como se vivem as vidas e delas extraem-se significações.

Porém, como percebemos? Como sentimos? Como reagimos? Só teríamos qualquer controle sobre os encontros que derivam em respostas para essas perguntas, se já soubéssemos de antemão as hipóteses que surgiriam, orientadas por princípios e concepções adotadas e tomadas como consenso.

Neste artigo, buscamos conectar filosofia e cinema no campo da educação, pensando a urgência de apontar fissuras para a constituição de sujeitos em uma trama de discursos que busca dizer das realidades em estruturas enredadas como verdade.

A vida, entendida e dimensionada como drama, não se resume numa linearidade causal, não responde a um fundamento de existência; ela se coloca insistentemente marcada por quebras em nossos estereótipos de verdade, que outrora considerávamos estabelecidos e estáveis, e que, em um instante, podem ser desmontados quando atacados por um acontecimento. Em nosso encontro com um acontecimento, a percepção pode desencadear outras organizações corporais pelas forças de desarranjos de sentidos.

Quando a univocidade do todo e da unidade se transmuta e nos mostra sua abertura, muitas vezes não sabemos como perceber, sentir e reagir. Isso ocorre, por vezes, em nosso encontro com algumas imagens que não vêm nos reiterar um padrão de comportamento ou associações conhecidas. Sentimos de um modo que afetaria nossa constituição, provocando-nos e insistindo a pensar melhor aquilo que nos toma, a revelar-nos uma consciência, mas uma consciência singular, que não há como se igualar de forma generalizada ou homogênea ao que nos cerca, fugindo de uma universalidade, afirmando diferenças e possibilidades de coexistências, não reduzidas ao Uno.

No campo das artes em seu estreito vínculo com as imagens, apostaremos neste trabalho em um tipo de imagem, que chamaremos de imagem-contraste —em uma conexão com as filosofias da diferença, e aqui, mais precisamente com a de Gilles Deleuze - a qual pensamos ser importante para a intensificação do entre polos: gênero, classificação, hábito, juízo. Um encontro com esse tipo de imagem poderia permitir o pensamento pensar no intervalo, escapando à recognição e à lógica, à identificação e ao reconhecimento imediato de gêneros e modelos estéticos universais. Parece possível, no encontro com imagens, termos uma oportunidade de sentir algo diferente, mas que ainda não necessariamente sabemos precisar o quê. E é exatamente por este movimento que a educação com as diferenças dá pistas de sua insurgência. 
Gilles Deleuze cria conceitos em filosofia privilegiando encontros. O encontro com Henri Bergson parece forte para possibilidades de apontar a importância dos devires, no percurso do vivente entre o atual e o virtual. Também há o encontro com Espinosa e a tentativa de garantir um pensamento imanente, importante para repensarmos o conceito de consciência, palavra forte em educação, muito atrelada à ideia de definir valores e juízos singulares, individuais e, simultaneamente, relançados aos que seriam universais, ao invés de permitir-nos sentir diferentemente. Quando atacados por um encontro intensivo, tal como o com força da arte, mais especificamente o cinema, podemos passar a sentir de outro modo e nos deslocarmos de figuras de pensamento.

O atual e o virtual em Deleuze são importantes para uma filosofia pensada na imanência, privilegiando um empirismo transcendental que preza pela intensividade dos encontros e, para nós, possibilita pensar que a educação também se faça por conhecimentos sentidos intensamente e não meramente em aplicações de formas e teorias. Pensamos ser importante a possibilidade de abertura de mais campos que privilegiem a invenção dentro da educação, que privilegiem a criação de conceitos, de blocos de sensações e, também, de funções, abrindo este campo para experimentação em/com os acontecimentos.

Argumentamos que o contraste, quando deslocado do campo de oposições, ganha força nas articulações entre imagens de campos distintos ao desfazer usos habituais. No caso do cinema, novas conexões entre a imagem visual e o som permitiriam ao público um momento de intervalo no entre de algumas cenas, em que sua sensibilidade poderia ser elevada a outros níveis de percepção e, consequentemente, poderia abrir a possibilidade de pensar um problema que um cineasta busca levantar com sua obra. Disparando modos de pensamento desmoldados de certos padrões, que poderiam desencadear uma consciência que se constrói sem se saber, previamente, a que destino, borrando a imagem de um sujeito estruturalmente constituído.

Desse modo, nosso encontro com filosofia e com a arte, no campo da educação, busca problematizar a necessidade da abertura da cognição ao vermos tensionadas codificações que buscam nos estruturar, e que, por vezes, paralisam potências de pensar. Potencializar uma educação em que se busque criar e se conectar a diferentes campos de afecção - afecto em um sentido deleuzianoespinosano - abrindo brechas para possibilidades de pensar para fora da necessidade já imaginada por outrem, e não apenas constituir juízos e treinar ações, aceitando o drama da vida e sua ilogicidade a-linear.

Para seguir com estas linhas plurais, propomos pensar uma educação que se conecte aos contrastes, em um encontro com as imagens do cinema e a filosofia de Gilles Deleuze, possibilitando pelo uso do humor e da ironia; esse é um modo de se afirmar o termo contraste, que associado às imagens, afirma a diferença, ao mesmo tempo em que dá condições de apresentar uma percepção no entre do tempo, desfazendo relações habituais entre imagens visuais e sonoras.

Se o encontro de Deleuze com o cinema torna possível que o filósofo francês pense e crie conceitos, reelaborando com eles uma interessante taxonomia das imagens cinematográficas — pela qual 
se preza por uma relação semiótica mais potente, aberta e plural — pensamos que um similar exercício e esforço de criação conceitual também possa ser tomado desde o campo educacional, para pensarmos uma educação com/pelas imagens e que se dedique ao enfrentamento da cognição, considerado um campo de interesse e influência para os sujeitos/ os vivente da educação.

\section{Contrastes e imagens audiovisuais}

Nos encontros com imagens, formamos inúmeras associações e correspondências em nossos percursos de vida pelos estados de coisas. Habituamos a perceber certas coisas de um modo e a reagir de uma maneira, mais ou menos, padronizada àquilo que percebemos. $\mathrm{O}$ cinema e a televisão não deixam de reforçar certos padrões de conduta com os quais alimentam comportamentos generalizados, conforme nosso reconhecimento do que nos é apresentado.

Por estarmos habituados a uma cultura que privilegia gêneros, muitas vezes, seria como se ao vermos cenas de comédia, de terror, de suspense, tivéssemos nesses encontros com imagens, modelos que nos permitiriam ver, reconhecer e agir por estarmos conscientes do que vemos. Em outras palavras, seria como se nosso pensamento estivesse modulado a um padrão de recognição que apresentasse respostas previsíveis ou identificáveis que, ora nos levassem adotar padrões, como por exemplo, de consumo; ora quisessem nos apontar uma crítica generalizada a estes padrões. Assim, conduzidos por um lado, ou conscientes de outro, adotaríamos posições ideais mais massificantes.

Mas, se a cognição se resumisse a esses padrões generalizantes de recepção e apreensão de coisas, teríamos que aceitar uma vida-robô, ou como alguns apontam, não escaparíamos de ser reduzidos em nossa existência a um estado 'zumbi', molde de consumo ou uma vida de rebanho. Ou, por outro lado, ficaríamos à espera de uma consciência capaz de tomar a todos em um mesmo discurso comum, idealizado. Neste caso, o contraste não escaparia de poder ser apenas enunciado como negação ou contradição das formas habituais, categorias identitárias e ideias essenciais. Não escaparia de só ser manifestado e reconhecido por formas de exclusão, 'ou isso', 'ou aquilo'.

Contudo, o vivente em seu percurso pelo plano de imanência não necessariamente percebe tudo, e muito menos, percebe do mesmo modo nos encontros com outras imagens. Esta capacidade de percepção seria ainda ampliada pelo cérebro que garantiria um intervalo entre a percepção e a ação, capacidade que, no humano, parece se desdobrar pela possibilidade de pensar.

Ao percebermos algo de uma imagem, não necessariamente a perceberemos de um mesmo modo. A ação que poderemos realizar ou não, não necessariamente será a mesma. Parece não ser possível uma consciência universal a respeito do que percebemos, o que nos afasta de apenas reproduzirmos respostas padrões que impliquem em comportamentos que garantam certa previsibilidade. Até porque não há consciência na imagem e, se essa consciência existe, ela se constituiria diferentemente em cada um de nós e não nos seria dada a priori. 
Em nossos encontros com imagens cinematográficas, mesmo que reforcem determinadas estruturas e arranjos convencionais de linguagem que tendam a uma certa constituição de um processo de subjetividade, compostas por leis de semióticas e estruturas psicológicas, parece não haver tanta razão para temermos uma massificação operada pela televisão e o cinema. Embora se montem padrões, não assimilamos o que nos é apresentado da mesma maneira e, parece que nem a informação que nos chegue possa garantir ações universalizantes.

Claro que dentro de uma linguagem, uma educação, uma política maior, há a tendência de generalização e de estabelecimento de categorias e padrões que tendam ao universal, mas mesmo nos constituindo conjuntamente com estes padrões que influenciam nossa subjetivação, a chance de desvios sempre pode acontecer no intervalo entre percepção e ação. Em nossos encontros com imagens, sentimos diferentemente, mesmo que reduzíssemos estes encontros aos encontros extensivos com os estados de coisas.

Também, ao nos deslocarmos pelos estados de coisas, as próprias coisas se apresentam de maneiras diferentes e parecem não poder ser reduzidas apenas a representações de modelos de vida. Isso nos permite já desconfiar de uma consciência universal dada por identificações que nossa inteligência captaria dos estados de coisas, pois estar consciente de algo diferirá de diversas maneiras a como cada um percebe algo, às diferentes conexões que cada um realiza ao percebê-lo, e também, como cada um comporá sua ação de acordo com a percepção que teve e o ponto de vista predominante, em um certo momento.

Vale ainda acrescentar que o vivente não está à parte do meio no qual ele percebe tal ou qual coisa, o meio também terá grande influência na relação que se estabelece com os encontros, pois sempre muda, o que também nos faz mudar percepções e ações, como também, intensificar e produzir continuamente diferenças. Quando o meio muda, mudam também as relações habitualmente estabelecidas, ao passo que também novas relações se atualizarão diferentemente em cada um, não consensualmente.

Aprendendo com Deleuze e Bergson que a consciência não viria como 'luz'. Essa não teria a capacidade de iluminar ou promover modos de agir ideais, já que não seria igual para todos, implicaria diferenças singulares que afetariam diferentemente cada um, além da multiplicidade de conexões que cada um poderá efetuar ou não. Em outras palavras, 'consciência de' não constrói em um coletivo de indivíduos condutas universais, existem sempre variações quanto à percepção, afecção e possível ação ao que fora percebido. Às vezes, em nossos encontros somos atingidos ou afetados intensamente, somos levados a um estado que não se reduz a um mero reconhecimento ou a um sentimento identificável, e que poderá nos fazer sentir de outro modo.

Os encontros com o cinema podem nos ajudar a pensar possíveis diferenças que nos ajudariam a perceber rachaduras de uma consciência universal relacionada a uma cognição centrada no reconhecimento de coisas, abrindo brechas-possibilidades de diferentes pensamentos se constituírem em 
seus diferentes ritmos modulatórios na imanência, privilegiando afectos que cada um possa vir a sofrer pelo percurso na extensividade, sem uma possível determinação dada a priori, instituída por um padrão, um método ou um projeto universal.

A filosofia de Deleuze e Guattari abre variáveis aos processos de subjetivação, possibilitando pensar que cada um, cada vivente em sua individuação singular e tomada de encontros plurais e intensivos, possa abrir e talhar criativamente seu mundo, sobre o plano de imanência. Também, o cérebro ajudará a prolongar o intervalo que se dá entre percepção e ação — no caso do humano, com uma maior complexidade — operando saltos que ajudarão a compor essa singularidade do vivente, já que nem sempre nós alcançamos a mesmas respostas no entre sinapses.

No pensamento de Bergson, exposto por Deleuze (2009) — aqui nos baseamos mais nas aulas do curso sobre Bergson, ditado por Deleuze - dentro dos intervalos ou brechas, ainda poderiam acontecer duas coisas. Em primeiro lugar, seguindo com a imagem-movimento, entre a imagempercepção e a imagem-ação, a brecha seria ocupada pela imagem-afecção. Assim, a imagem-afecção ocupa a brecha, mas não a preenche. Em segundo, o que vai preencher a brecha é a imagem-mental, como o pensamento trabalhará em decorrência de um afecto sofrido. Por vezes, bastará um reconhecimento para montar a ação que se desenvolverá - estabelecendo uma operação de recognição; por outras, o pensamento será elevado a outra potência, sendo necessário inventar uma nova ação, que logrará em algumas tentativas e falhará em outras, quanto a resposta que busca apresentar. O afecto é o que dá chance de a cognição pensar o todo e inventar o novo.

\section{Encontros - uma dramatização da vida}

Em nossos encontros com as imagens do cinema, ao percebermos algo, às vezes somos afetados com mais intensidade. Essa intensidade, no entanto, não é localizável, nem mensurável, mas nós precisamos de algum modo inventar como dizê-la, criar com ela, pois a afecção em si não nos dá uma resposta. O trabalho de nossa mente, em como dizer isso ou aquilo, pode levar à criação de algo: de um conceito, de um bloco de sensações, de funções — tal qual Deleuze e Guattari (1997) apresentam ser o trabalho de criação das Caoides ou as filhas do caos: a filosofia, as artes e a ciência — bem como, inventase a própria vida.

A vida, aberta ao acaso e à contingência, torna-se possível de ser problematizada, de se compor por uma estética que privilegie os acontecimentos que a tomam; ela é inseparável de uma ética e de uma política dos afetos que se faz na imanência. Não apenas se compõe de consensos, de relações ideais harmônicas, de imagens mentais universais; a vida se compõe de divergências entre os fluxos que a tomam, entre as nuances que se afirmam por contrastes e que não necessariamente se opõem, desfazendo e desmontando padrões ideais estéticos, já que as imagens em si não carregam nenhuma consciência. A vida é criada nas potências dos dramas que a tocam, entre lutas, entre danças das forças de composição 
que se modulam entre acasos e devires que rasgam e rasuram moldes da consciência humana, possibilitando com que cada um refrate ou reflita, diferentemente, intervalando as continuidades causais e compondo suas próprias imagens mentais.

Contrastes extremos entre imagens, ao invés de construírem um olhar que identifique e reconheça diferenças, parecem apontar coexistências possíveis de diferentes conexões que possam se compor e que não necessariamente levarão à mesma organização mental e a consciência de algo. Talvez, possa levar a uma consciência que não venha 'de' algum lugar, mas que aconteça 'em' nós, pelo contínuo e não linear caminhar pela imanência, entre todos os encontros que realizamos pela vida, afirmando no vivente uma variação complexa contínua, pensamento que temos como intercessores Bergson e Deleuze, mas, neste momento, sobressalta-se o texto O Método de Dramatização (DELEUZE, 2006).

Ao entrevistar o filósofo Luiz Orlandi ${ }^{1}$ (NOVAES, 2012), que também traduziu o referido texto de Deleuze, buscamos adensar e estender linhas do entre filosofia e arte no campo da educação, e que considera importante a ideia de 'encontro' para se experimentar pensar a ideia de contraste. Segundo Orlandi, 'O método de dramatização' é um texto em que Deleuze busca garantir sua filosofia sem cair em um empirismo puro e vincular a vida apenas relacionando-a a reconhecimentos de formas que constituem saberes, como também possibilitaria não cair em uma pura transcendência.

Naquele texto, Deleuze apresenta o termo diferenciação complexa contínua, termo pertinente para apresentar a vida do vivente não meramente a uma disposição do reconhecimento das diferenciações dos estados de coisas, como também apresentar que em certos encontros do vivente com um estado de coisa, o vivente tem uma percepção intensificada, em que precisa ter o que dizer, o que criar. O vivente está sempre a se encontrar com o que reconhece em seu percurso pelos estados de coisas, mas às vezes um encontro o toma de tal maneira que ele precisa criar, inventar algo que ele ainda não sabe o que é. Pode-se dizer que isso é ter uma ideia.

Segundo Orlandi (NOVAES, 2012), a filosofia de Deleuze é uma “filosofia dos encontros", pois Deleuze está sempre a se encontrar com outros filósofos, escritores e artistas para criar sua filosofia. Como sabemos, para Deleuze e Guattari (1997), a tarefa da filosofia é criar conceitos, para criar conceitos é preciso ter uma ideia. O que é uma ideia? A ideia é uma imagem (DELEUZE; GUATTARI, 1997).

Porém, os encontros não são lineares, muitas vezes neles tendemos a reconhecer coisas e identificá-las. Como apontamos, no caso do vivente-humano, este possui um cérebro que dá a chance de não recebermos outras imagens de uma mesma forma, como em um circuito fechado. Às vezes, no encontro com estas imagens, sentimos diferentemente e produzimos uma nova ação. O pensamento vai além do entendimento, ele cria, e ao criar, transpassa o esperado, inventa o novo. Não seria este um processo dramático?

\footnotetext{
${ }^{1}$ Entrevista realizada no dia 24/06/2013 com Luiz Orlandi durante a elaboração desta dissertação e que teve a intenção de entender melhor como se daria a ideia de encontro em Deleuze.
} 
Nas artes, o drama está relacionado à quebra das relações de formas de composição que tendem ao lírico. Trata-se do que, por exemplo, a artista Fayga Ostrower (2013, p. 40) encontra na obra de Van Gogh para apontar que o conteúdo expressivo dramático, alcançado pelo pintor holandês, deriva não apenas dos motivos (assuntos) elegidos — que segundo ela, tendem a valorização da vida: "símbolos de vitalidade e produtividade da Natureza (o sol, os campos, o semeador, a colheita, as flores) — mas, sobretudo, eles são conquistados: "na elaboração formal das imagens” (isto é, na transformação do assunto em conteúdo expressivo), criando grandes tensões espaciais, pela intensificação rítmica de linhas e pinceladas, e também pelas cores altas e vibrantes, que ele harmoniza em relações complementares” (p. 40).

Assim, pensamos ser possível dizer que Van Gogh afirma a vida em jogos de forças rítmicos e colorantes de suas pinceladas, atualizando e intensificando motivos pelo uso de contrastes, em conexões imanentes que o pintor estabelece com essas forças e que se mantêm presentes no todo do quadro. A criação artística de Van Gogh é pura vibração, potencialização de vida, não merecendo ser reduzida à aspectos psicológicos e problemas de sua vida pessoal. Também, vale-se ressaltar, que um artista ao apresentar sua obra, o faz atravessado por pensamentos e discursos estéticos e políticos, distanciando-se mais ou menos das formas usuais de reconhecimento em que expressa através da linguagem que busca apresentar ou representar. A imagem criada pelo artista pode nos dar o que pensar, de todo modo, nem obra, nem criador, terão controle sobre as sensações que podem ser despertadas, porém, a sensação sempre pode propiciar o intervalo necessário em que um sentimento é potencializado como um novo afeto e alguém passa a perceber de um outro modo, possibilitando uma consciência em experimentação com o que está longe da forma identificável, habitual e generalista de conhecimento, propiciando, talvez, uma consciência que flerta com o acaso e as desterritorializações do sentir. Desse modo, o artista lança sensações ao mundo, para além de sua pessoalidade cognoscente, o que não o impede de lançar suas próprias apostas e crenças ao mundo, seguramente, há de se acreditar na vida e em seus possíveis imbricamentos éticos, ou melhor, "estéticos” (LINS, 2021).

Ao acreditar na força da imagem, nem sempre basta investigar se ela instaura o drama ao articular diferentes linguagens e quebrar com o lírico. Sabemos que para muitos é importante buscar se este drama problematiza uma situação de dominação, questiona certo modo pelos quais as pessoas pensam, vivem, sentem e a maneira pela qual ela ou ele fazem isso. Como também pode ser importante pensarmos se um encontro com o que é expresso na quebra de um lirismo poderia possibilitar acontecimentos que vão além do localizável, identificável, além da consciência de algo.

Algo que poderia nos afetar a sentir de outra forma, não por mera reflexão ou ilustração semiótica, e sim, numa outra apresentação semiótica que possa não apenas se fazer refletir claramente ou idealmente, mas que se componha com certo embaraço do modo dominante de leitura, interpretação e percepção, provocando o pensamento a pensar outras formas de conhecimento e entendimento das várias possibilidades de efetivações de mundos e de imagens que possam vir a existir. 
Quanto ao cinema, Deleuze (2018) nos diz que

O cinema não é uma língua, universal ou primitiva, nem mesmo linguagem. Ele traz à luz uma matéria inteligível, que é como que um pressuposto, uma condição, um correlato necessário através do qual a linguagem constrói seus próprios objetos (unidades e operações significantes). Mas esse correlato, mesmo inseparável, é específico: consiste em movimentos e processos de pensamento (imagens prélinguísticas), e em pontos de vista tomados sobre esses movimentos e processos (signos pré-significantes) (DELEUZE, 2018, p. 379).

Busca-se nesse contínuo estudo do contraste que se ensaia neste texto, sobretudo ao pensar algumas possibilidades apontadas no cinema moderno e contemporâneo, momentos em que o drama é marcado por outras conexões imagético-sonoras que façam pulsar outros signos, mesmos que causados no choque da representação por ela mesma; movimentos que possam causar uma imobilidade reativa no próprio esquema sensório-motor e acordar uma dimensão virtual-intensiva. Provocar e potencializar o pensamento quando atacados por sensações intensificadoras que, por vezes, marcam ou modificam a maneira em como se estabelecem o drama e a conexão que podemos sentir quando afetados, ao problematizar a vida.

O cinema tem a possibilidade de questionar figuras de pensamentos expressas em discursos de verdade, colocando-as em choque ao deslocar o meio tal qual elas foram criadas, abre brechas em discursos apoiados em uma constituição lógica da verdade às outras possibilidades e diferentes pontos de vista, em relação ao mundo, por vezes, de modo irônico. Acreditamos que haja um jogo do contraste construído junto à ironia que, de quando em quando, mais do que buscar estabelecer o humor como um jogo que consolide hierarquias ao provocar o riso com base na humilhação e desprezo pelo outro, façase mais por uma construção que busca desmontá-las, revertendo um falso princípio superior — que se buscava legitimar pelo riso - através da intensificação dos jogos de força que o humor traça na imanência.

Às vezes, faz-se a crítica da ironia ao dizer que ela pode não ser diretamente assimilada, entendida, não causar o efeito do discurso desejado, ou ainda, reforça-se o uso da ironia como legitimação de um preconceito sobre outrem. Mas será que também não é interessante colocar o pensamento em choque por fazer variar as formas de discurso, invertendo elementos de uma gramática de semiologia, fazendo a ironia trabalhar em um desmonte das relações que colocavam ela mesma nesta condição de superioridade? Não seria importante levantar dúvidas, além da tentativa de garantir um entendimento linear, explicativo, consciente? Pensamos que discursos de verdade, predominantes na modernidade e que o cinema atualiza na tela, podem ser balançados por contrastes, intensificados por outras conexões entre a música (e o som) junto à imagem visual, às vezes, trazidos com uma sutileza irônica que ajuda a potencializar a cena dramática. 


\section{Stanley Kubrick: a sutileza da ironia em um possível confronto com a natureza humana}

Alguns cineastas utilizariam arranjos ópticos e sonoros em seus filmes - que chamaremos de contrastantes - com os quais poderiam potencializar muitas de suas cenas ao quebrar com o que seria a "esperada" junção entre trilha sonora e a imagem visual, problematizando-as. Questionariam certa natureza humana, constituição humanizada de mundo, ou apresentariam uma subjetividade menos fixa e regulada em suas apreensões, ao deslocá-la e movimentá-la, assinalariam uma natureza inesperada posta em devir.

Cenas de guerra parecem potencializar outra 'natureza humana' em que a moral é levada a se deslocar de um estado ideal, puro e fixo. Parecem mais sensíveis às condições cambiantes do meio, ao apresentarem comportamentos não validados moralmente, ou não psicologicamente aceitos. $\mathrm{O}$ cinema conseguiria nos dar imagens que nos afetam mais sensivelmente do que idealmente. O que não quer dizer deixar de trabalhar com apresentações de consciência, mas seria uma consciência que se faria sentir e não uma consciência dada em um discurso ideológico ideal. A ideologia, se apresentada, viria por imagens, mas nossos encontros com essas imagens não necessariamente transmitiriam o discurso, poderiam sim, fazê-lo sensível. Em outras palavras, a forma apresentada em imagem parece, desse modo, não funcionaria idealmente, mas sensivelmente. No entanto, acabaria o trabalho da transmissão da ideia apenas no sensível concreto? Poderia a consciência ser introjetada em corpos imaginados universais, respeitando fórmulas de montagem e jogos de câmeras? O real se esgotaria nas relações organizadas que articulam as estruturas dos estados de coisas?

Kubrick (1973) nos lança a questão do humano em outro tempo (tempo do cinema) em que ele busca que as pessoas confrontem a si mesmas nas imagens apresentadas na tela ${ }^{2}$. O cineasta ainda preza por tentar mostrar situações que soem mais reais possíveis, apresentando rasuras no discurso de uma sociedade de segurança, sobretudo a sociedade americana, em que as pessoas pudessem receber questionamentos em suas visões ideais de mundo, propiciados por imagens com um senso poético que colocariam o tempo em tensão ${ }^{3}$. Soaria já interessante pensarmos que tempo ou tempos poderiam nos tensionar. Problema que já apresenta uma dica quanto à insuficiência de um tempo cronológico articulado a uma memória fixa.

Deleuze (2017) já mostrara que Espinosa nos colocava que o homem ao escolher viver em sociedade precisaria renunciar a seus direitos naturais. A cidade, a civilização e suas instituições impõem outros meios para assegurar certa existência e os valores que nascem e morrem dentro dessas. Na guerra o meio construído por uma certa civilização muda, como também se mudam os valores e isso não ocorre de uma só vez, de maneira igual para todos, mesmo que por necessidade.

\footnotetext{
${ }^{2}$ Kubrick, S. Entrevista. Disponível em: http://www.youtube.com/watch?v=xa-KBqOFgDQ. Acesso 19/06/21.

3 idem
} 
As obras de Stanley Kubrick parecem nos apresentar, em imagens, conflitos da natureza humana, ao colocar a necessidade de mudança de natureza do homem civilizado para a natureza do homem da guerra. Mas como apresentar isso em imagem? Como demonstrar essa mudança sem ser apenas por jogos psicológicos em relações de montagem? Como mostrar o momento em que o ser humano deslocado de seu meio, adapta-se e adquire novos valores, no caso, valores necessários para a sobrevivência em meio à guerra? A ironia apresenta-se como uma forma de exprimir um pensamento, ao questionar um hábito, acrescentando algo a mais, invertendo posições rígidas e, parece forte para se desmontar certas verdades, ou ao menos criar um vazio, um intervalo entre a percepção e uma possível reação. A ironia nos filmes de Kubrick pincela, muitas vezes, um toque de humor que flerta com o absurdo e interrompe o lírico caminhar de uma certa visão de sociedade, no caso, a sociedade estadunidense; bem como, parece nos apresentar a necessidade de não se levar a sério demais os fatos e abrir brechas para outras percepções.

Em uma das cenas da segunda parte do filme Nascido para Matar (Full Metal Jacket, KUBRICK, 1987), apresenta-se os soldados na guerra, entrincheirados, com explosões ao fundo, tiros de tanques de guerra, corpos sendo carregados em macas, ao mesmo tempo em que são filmados por soldados repórteres. Com todo esse movimento caótico que recria um possível momento da guerra contra o Vietnam, os fuzileiros que são filmados aparentam despreocupação e demonstram até certa descontração como se tudo que acontecesse fosse comum ou banal, acostumaram-se ao absurdo. A trilha sonora nesta hora acentuaria o contraste irônico, como se tudo o que se passasse pelas imagens confirmasse essa casualidade comum e já internalizada como hábito pelos soldados: corpos carregados, bombas, tiros etc. Uma sutil ironia que não implicaria em conduzir a uma ascese da verdade, mas que poderia abrir uma fenda em consciências fixadas e modular percepções dadas ao movimentá-las, desarranjando percepções de si mesmo e dos outros. Parece-nos propor um convite a inventarmos outros 'sis', outros 'outros'.

Kubrick parece também nos provocar a pensar e a sentir se conseguiríamos suportar uma falta de valores em uma sociedade pacificada. É famosa a cena em Laranja Mecânica (KUBRICK, 1972), na qual o protagonista Alex canta "I'm singing in the rain" ${ }^{5}$ enquanto comete um estupro; neste ponto o contraste entre imagem e som é marcadamente forte, evidenciando ainda mais a dramaticidade da cena, provocando sensações marcantes de conflito. Disjunções sonoras e visuais habituais que marcariam ou instaurariam o drama com uma rasura no próprio gênero. Até quanto conseguiríamos tolerar os extremos?

O contraste operado por uma desterritorialização irônica aparece nesse ponto em que se inverte a relação óptica e sonora lógica, em sua junção esperada em um movimento de clichês. Desterritorializar

\footnotetext{
${ }^{4}$ Em seu livro, A invenção de si e do mundo (1999), Virgínia Kastrup investiga o problema da invenção reduzida à inteligência nos estudos de cognição. A autora enfatiza a necessidade de se pensar a cognição para além de finalidades úteis ou apenas vinculadas à aquisição do conhecimento, e busca potencializar a problemática de uma política inventiva que "tem de lutar permanentemente contra as forças, em nós e fora de nós, que obstruem o movimento criador do pensamento" (p.238) que acreditamos passar também por uma política que permita outras práticas/experiências de viver.

${ }^{5}$ Letra de Arthur Freed e música de Nacio Herb Brown
} 
a lógica que baliza um certo entendimento da verdade, atrelada a uma constituição progressiva do humano, frente a um molde de civilização, é algo que Herzog (1973) já tensionava com a solução inventada por Kasper Hauser — “você é um sapo?” — quando esse personagem reponde a uma pergunta inquestionávet, e que admitia apenas uma solução, ao ser testado por um professor de lógica que avaliava seu processo de humanização e civilização. As obras de Kubrick parecem também tensionar perguntas e respostas sobre os processos de subjetivação humana, lançando-nos em um vazio, em uma flutuação moral e ética que poderia relançar, diferentemente, a pergunta de Kasper para nós: "você é um bom humano?".

Nas obras de Kubrick, opera-se uma certa disjunção dos clichês aos quais as imagens estariam habitualmente atreladas, por exemplo, cena de violência conectada a uma música agitada ou que evoque uma predisposição para um tempo em tensão, ou ainda, a apresentação de uma música suave que evoque um sentimento de alegria para reforçar uma situação em que se busque esse tipo de emoção são, pois, invertidas, como que buscando um desarranjo dos clichês, aos quais os sentimentos se viam acomodados por certo hábito, em se buscava figurá-los dentro de uma lógica de representação, tendendo a construir um encadeamento de cenas relacionadas a modelos de reconhecimento normatizados e organizados.

Talvez, os questionamentos sobre o humano, ao expô-lo a condições complexas, às vezes em meios inóspitos, intensifiquem uma mirada para a vida que não corresponda ao lirismo. Francis Ford Copolla, no documentário realizado por Eleonor Coppola Francis Ford Coppola: O Apocalipse de um cineasta (COPPOLA, 1991), aponta as transformações internas nos diferentes níveis de bem e mal de um homem, até chegar a outro ponto, mudança de qualidade que torna alguém um assassino, mas não a figuração sentimental do assassino, o que aponta é a desconstrução do bom humano por sentimentos não localizáveis, dados pelos afectos sentidos na guerra (não pela guerra), o que surge é, então, um humano que se traça em meio à guerra e tem com ela uma conexão que a memória da cidade não pode segurar em seu molde. Mas essa mudança de qualidade não transforma o meio, nem o meio transforma os outros de uma mesma maneira necessariamente, novas qualidades intensivas se atualizam na extensividade, nos estados de coisas, sem conformidade. Um acontecimento forâneo, um encontro intensivo com um afecto, continua a insistir complexamente e diferentemente, em uma nova composição desarranjada e conflitante que ocupa um espaço, diagramando-o. Algo surge e uma luta constante para descobri-lo se inicia, muitas descobertas não coincidentes virão.

Um exemplo dessas disjunções ópticas e sonoras trazidas, dessa vez, por Francis Ford Coppola, é a cena do filme Apocalipse Now (COPPOLA, 1979) - filme que deu origem ao documentário que abordamos acima, dirigido por sua esposa Eleonor Coppola (1991) —em que o cineasta estadunidense cria uma imagem de um ataque de helicópteros a uma vila vietnamita, intensificando-a com a música "Cavalgada das Valquírias" de Wagner. Seria essa uma cena que nos atualizaria o perigo do nazismo?

\footnotetext{
6 HERZOG, W. O Cenas - O Enigma de Kaspar Hauser (1973). Disponível em: http://www.youtube.com/watch?v=oAnOiOfnxuE. Acesso 02/06/2013.
} 
A obra de Coppola (1979) também afirma uma necessidade do humor irônico, deixa bem claro que nunca se tratou de se fazer um documentário sobre o Vietnam, até a escolha do lugar de filmagem as Filipinas - confirma isso. Precisa captar aquela natureza da guerra, o homem da guerra, as mudanças de valores que atinge cada personagem de um modo diferente, apresentar o horror, mas também a vida para além do lirismo, quando deslocada de seu curso idealmente programado.

É interessante colocar que tanto Laranja Mecânica como Apocalipse Now são baseados em obras literárias, mas o que se apresenta na tela não é a transposição de um livro. Seus diretores sabem que a imagem cinematográfica não é texto e tampouco se trata de melhorá-lo. É necessário pensar suas próprias imagens, no caso dos dois, Copolla e Kubrick, o mais real possível, tornar confrontos da alma visíveis em lugares críveis e nos provocar a pensar também pela ironia, afinal não precisamos perder o humor, esse só não precisa vir em uma forma ideal, feliz e em concordância a um sorrir codificado, o homemguerra não é o homem humanizado, sua animalidade necessita falar mais alto, ou às vezes, manter o máximo de silêncio possível.

Quem recebe uma das cenas citadas poderia, talvez, perceber-se como mais complexo e singular, sentir a crueldade mais próxima, no corpo e não boiando ou flutuando em algum plano ideal. O cinema nos ajuda a exprimir tipos de pensamentos na forma de imagem que, às vezes, valem muito mais do que a história que passa por trás.

Aqui não se trata de se fazer um elogio à guerra, ou que queiramos devolver a animalidade e brutalidade ao homem; o que buscamos considerar é que o cinema pode nos apontar de modo irônico a fragilidade de um projeto de humano, também excessivamente cruel. Crueldade que sabemos muitas vezes ser operada por dispositivos moduladores que podem acarretar muitos sofrimentos, que reduziriam, inclusive, as potências humanas ao tentar lhes arrancar a capacidade de pensar e com ela de operar escolhas, nem sempre lógicas.

Ao mesmo tempo, essa imagem-contraste, apresentada pelo cinema entre disjunções sonora e visuais, busca mais criar momentos de intervalo, em que tenhamos a possibilidade de sentir-pensar sobre nossa própria constituição, sem deixar de rirmos e indagarmos sobre nós mesmos. Neste sentido, a obra de Kubrick privilegia um elogio à ironia e que, como aponta o professor e pesquisador em estudos fílmicos Robert P. Kolker (2018), em uma conferência intitulada Stanley Kubrick - The Irony of Feeling, parece ser um engano atribuir aos filmes desse cineasta aspectos que os reduzam a busca por instaurar sentimentos relacionados a certa frieza ou tristeza. Segundo Kolker (2018), nas obras de Kubrick, "quanto mais o espectador tenta chegar a um acordo com o que é visto e sentido, mais a distância e o isolamento são impostos a ele. [...] Quanto mais distância e isolamento o filme pode criar, mais é sentido, mais é vivenciado, mais há para responder".

Para Kolker (2018), a obra de Kubrick é “visionária, cria imagens extraordinárias”. A força dessa visão estaria "na capacidade de seus filmes buscarem: 
nos fazer querer ver, não virar as costas, mas ver de uma forma que é mais incomum no contexto das convenções cinematográficas. As emoções são geradas para atos e/ou invenções - de cabeça para baixo, se você quiser. As emoções estão dentro ou abaixo da superfície irônica, do muito visto, daquela superfície complexa que, tantas vezes, acusou os filmes de Kubrick de serem frios (KOLKER, 2018) .

Kolker (2018) destaca que os filmes de Kubrick são centrados nas personagens, personagens que não necessariamente nos dão pena, e mesmo que, às vezes, sejam abjetos ou repugnantes como Alex (em Laranja Mecânica) ou o sargento Hartman (em Nascido para Matar), esforçam-se para triunfar em sua inusual forma de estar no mundo, porém, "as ironias de seus esforços são frustradas por meios absurdos, em circunstâncias extraordinárias."

Nascido para Matar (KUBRICK, 1987) traz, segundo Kolker, aspectos que não deixam de apresentar a guerra como "inferno", mas o modo irônico que Kubrick realiza a criação de suas imagens permite que essas também possam ser "entendidas como um produto de bufonaria e confusão". Acreditamos que esse filme é uma obra privilegiada que permite mostrar uma dobra da ironia por ela mesma.

Na primeira parte do filme, Hartman se esforça em fazer com que seus futuros soldados virem homens de combate. Para tanto, não deixará de humilhá-los, de rebaixá-los, de usar a ironia para transformálos em homens da guerra, por onde reforça-se a superioridade masculina, o sexismo, os preconceitos, a superioridade estadunidense sobre os outros povos. Já na segunda parte do filme, que se passa no Vietnam, os soldados terão toda aprendizagem, os ensinamentos de Hartman, postos à prova. Se a cena comentada por nós, anteriormente, mostrava uma certa adaptação e tranquilidade dos soldados ao novo meio, reforçada por uma música contagiante, Kubrick, mais ao final do filme, quebrará essa falsa ilusão. Um pelotão de soldados se verá emboscado por um atirador de elite que, pouco a pouco, os vai dizimando, fazendo saltar o medo, o terror, a sensação de que nada está sob controle. Após várias mortes, os soldados conseguirão atingir e ferir gravemente o atirador, capturando-o. Surpreendidos, descobrirão que se trata de uma mulher, algo inimaginável pelos ensinamentos que receberam de Hartman.

Ainda nesta cena, a atiradora de elite, agonizando em dor, implora por sua morte, caberá ao personagem principal, Jocker, a decisão de sacrificá-la. Por todo filme, Kubrick (1987) apresenta a Joker entre dualidades, o personagem é um paradoxo que carrega consigo a dualidade humana, tanto que leva, conjuntamente, o lema dos fuzileiros escrito em seu capacete "Nascido para matar", bem como um boton em seu uniforme e que traz o símbolo da paz. Posto em conflito, por fim, Joker matará a atiradora. A cena encerra-se com o cenário de guerra em chamas e os soldados cantando a música tema de Mickey Mouse, enquanto marcham, evidenciando um desarranjo harmônico e elevando os sentimentos a sensações não localizáveis. 


\section{Sujeitos da educação, em contrastes}

Pensamos que nem sociedade, nem ideologia, e vale também dizer, nem educação, fixam o humano em uma estrutura; ele sempre vaza, mas não vaza nem como gás, nem como líquido. Essas singularidades que vazam e compõem um todo chamado ser humano não se homogenizam no universal, mas, conseguem se compor no real, parece que jogam mais por efeitos de concordância e discordância operando escolhas que tensionam o tempo e o espaço continuamente, mas também complexamente, buscando sempre mais vontade de existência, insistem em existir e podem causar alterações no todo. Sabemos que com Deleuze e Bergson o todo aberto parece melhor corresponder à complexidade do vivente. Poderíamos dizer que sempre há uma chance de mudança de qualidade que deslocaria o humano e o que comporia, diferentemente, no desarranjo e aglutinações de forças dinâmicas e diferenciais.

Às vezes, certa ironia pode nos alertar sobre esse possível equívoco em se pensar o ser humano como uma unidade estruturada em sociedades dadas, ou controladas. Não seria a ironia um tipo de contraste do clichê pelo clichê que pode apontar rasuras de uma "verdade" mal colocada? Poderia haver certo confronto no pensamento - até pela forma de filmar - que prezasse por lugares que pareçam os mais reais possíveis e que aponte o quão fracassado pode ser um projeto que leve em conta um molde de humano descontextualizado das ligações espaços-temporais com seu meio, mas que também mostre a despontencialização das possibilidades de escolhas, mesmo que morais, ao rebaixar alguém abaixo do humano, em nome de um bem maior, como no caso da 'cura' de Alex, em Laranja Mecânica (KUBRICK, 1972). Estruturar um humano adequado não deixaria de ser uma microguerra contra certa natureza não humanizada.

Já em Nascido para Matar (KUBRICK, 1987), o diretor intensifica as relações comuns e preconceituosas realizadas pela ironia, mostradas na primeira parte do filme, por uma intensificação da ironia por ela mesma. Fazendo-a desmontar sentimentos banalizados em relações de aprendizagens fílmicas e televisivas, como no caso do uso da música tema de Mickey Mouse, ao criar novas conexões entre imagens visuais e sonoras que flertam com o deboche, ironizando a ação estadunidense na guerra do Vietnam e seus modelos de subjetivação. O cineasta instaura um novo campo de subjetivação audiovisual pelo vazio, o pelotão mesmo dizimado tentará, em uma recognição infantil com essa música, não se perder em meio à ruína da guerra. Um uso do clichê que opera contornos que nem um riso poderia ser sugerido ao telespectador, a alegria Disney, atualizada pelo canto e marcha dos soldados, revela toda uma paixão triste que se vincula ao medo para fingir que esse não existe — "não tenho medo", cantam os soldados, mesmo que apavorados e perdidos momentos antes. A representação rui porque o clichê, quando desmoldado, não se adapta à estrutura da guerra, o falso rosto confiante dos soldados, reproduzirá um aprendizado de uma fisiognomonia, que já foi desmontada pelas sensações. 


\section{REFERÊNCIAS}

COPPOLA, F. F. Apocalipse Now [filme] Direção: Francis Ford Coppola. EUA: American Zoetrope Studios, 1979. DVD/color/153 min.

COPPOLA, E. Francis Ford Coppola: o apocalipse de um cineasta. EUA: Zaloom Mayfield Productions e American Zoetrope, 1991. DEC/color/96min.

DELEUZE, G. O Método de dramatização. Trad. Luis B. L Orlandi. In: A Ilha Deserta. São Paulo: Iluminuras, 2006, p. 129-154.

DELEUZE, G. Cine I: Bergson y las imágenes. Trad. Sebastián Puentes y Pablo Ires. Buenos Aires: Cactus, 2009.

DELEUZE, G. Espinosa e o problema da expressão. Trad. GT Deleuze - 12, Coord. Luiz B. L. Orlandi. São Paulo: Editora 34, 2017.

DELEUZE, G. A imagem-tempo - Cinema 2. Trad. Stella Senra. Rio de Janeiro: Editora 34, 2018.

DeleuZE, G.; GUATTARI, F. O que é filosofia. Trad. Bento Prado Jr. e Alberto Alonso Muñoz. Rio de Janeiro: Editora 34, 1997.

HERZOG, W. O Enigma de Kaspar Hauser (1973). Question of Logic Scene - Kaspar Hauser. Disponível em: http://www.youtube.com/watch?v=oAnOi0fnxuE. Acesso em: 26/06/2021.

KASTRUP, V. A invenção de si e do mundo. Belo Horizonte: MG: Autêntica, 2007.

KOLKER. R. Stanley Kubrick, The Irony of Feeling. National Gallery of Art. 14 de nov. de 2018. 1 vídeo (45:12min). Disponível em: https://www.youtube.com/watch?v=2QKi9QBHfHc. Acesso em 27 jun. 2021.

KUBRICK, S. Laranja mecânica. [filme]. Direção: Stanley Kubrick. EUA: Warner Bros, 1972. DVD/color/136 min.

KUBRICK, S. Nascido para matar. [filme]. Direção: Stanley Kubrick. EUA: Warner Bros, 1987. $\mathrm{DVD} /$ color/116 $\mathrm{min}$.

LINS, D. Estética como acontecimento. São Paulo, Lume Editora, 2021.

NOVAES, M. Entrevista com Luiz Orlandi. 2012.

OSTROWER, F. Acasos e criação artística. Campinas: Editora da Unicamp, 2013. 